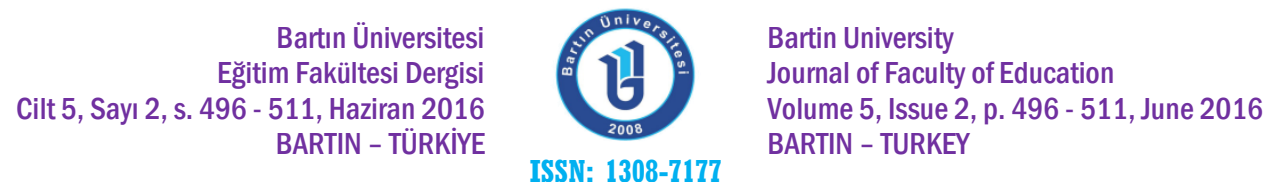

Doi: 10.14686/buefad.v5i2.5000175441

\title{
Öğretmenlerin Ruhsal Zekâsı ve Örgütsel Bağlııkları: İş Memnuniyetinin Aracılık Rolü
}

Ahmet Cezmi SAVAŞ, Doç. Dr., Zirve Üniversitesi, Eğitim Fakültesi, cezmisavas@gmail.com

Necati ÇOBANOĞLU, MEB, necaticobanoglu@hotmail.com

Öz: Bu araştırmanın amacı öğretmenlerin ruhsal zekâları ve örgütsel bağlılıkları ilişkisinde iş memnuniyetinin bir aracılık etkisinin olup olmadığını ortaya koymaktır. Bu amaçla Malatya ilinde devlet ilkokullarında görev yapan sınıf öğretmenleri arasında basit seçkisiz yöntem ile seçilen 155 öğretmen araştırmaya dâhil edilmiştir. Veriler Ruhsal Zekâ Ölçeği, İş Doyum Ölçeği ve Örgütsel Bağlılık Ölçeği ile toplanmıştır. Toplanan veriler SPSS 17 programı ile çoklu doğrusal regresyon yöntemi kullanılarak analiz edilmiştir. Sonuç olarak öğretmenlerin sahip oldukları ruhsal zekâ onların iş memnuniyeti düzeylerini ve örgütsel bağlılık düzeylerini olumlu yönde etkilediği görülmektedir. Ayrıca ruhsal zekânın örgütsel bağııı̆a etkisinde iş memnuniyetinin aracılık etkisi bulunmuştur. Sonuçlar ışığında, okullarda öğretmenlerin iş memnuniyetini ve örgütsel bağlılı̆ını artırmak için yöneticiler öğretmenlerin ruhsal zekâ düzeylerini göz önünde bulundurmalıdır.

Anahtar Kelimeler: ruhsal zekâ, iş memnuniyeti, örgütsel bağlılık, aracılık etkisi, öğretmenler

\section{Spiritual Intelligence and Organizational Commitment of Teachers: Meditaion Role of Job Satisfaction}

Abstract: The aim of this research is to determine the mediation role of job satisfaction of teacher on the relationship between the spiritual intelligence and organizational commitment. For this purpose, 155 teachers were chosen by simple random sampling methodology among primary teachers of public primary schools in the province of Malatya. Data was collected through the Spiritual Intelligence Scale, Job Satisfaction Scale, and Organizational Commitment Scale. The collected data were analyzed by using a multiple linear regression with SPSS 17. As a result, the spiritual intelligence levels of teachers have positive effect on their job satisfaction and organizational commitment levels. In addition, job satisfaction has a mediation effect on the influence of spiritual intelligence on organizational commitment. In schools, the managers should consider the spiritual intelligence of teachers to improve their job satisfaction and organizational commitment.

Key Words: spiritual intelligence, job satisfaction, organizational commitment, through the influence of teachers 


\section{GiRiş}

Çağdaş örgütler çalışanların maddi olarak kendilerine bağlı olmalarının yanında manevi olarak da bağlı olmalarının önemli olduğu bilincindedirler. Bu bakımdan çalışanlarının maddi kazançları sayesinde duydukları memnuniyet kadar, ruhsal anlamda doyuma ulaşıp ulaşmadıklarını da inceleme ihtiyacı duymaktadırlar. Çünkü örgüte bağılıık duymayan bir çalışanın ne kadar verimli olup, etkili işler çıkaracağı büyük bir soru işaretidir. Yeni yönetim anlayışında işinden memnuniyet duymak, örgütüne bağlıık duymak önemli bir sermaye olarak değerlendirilmektedir (Korkmaz, 2011; Serin ve Buluç, 2012; Valentine, Godkin ve Lucero, 2002). Günümüz örgütlerinin sadece maddi değerleri değil, çalışanlarının ve toplumun örgüte verdikleri manevi değer de ciddi bir sermaye olarak kabul edilmektedir. Her örgüt çalışanlarının yaptıkları işlerden memnuniyet duymasını, örgüte maddi ve manevi olarak bağlılık hissetmesini ister. Yönetim bilimleri de bu konularla yakından ilgilenmekte ve çağdaş örgütler için çözümler üretmeye gayret etmektedir (Hoy ve Miskel, 1987; Robbins ve Coulter, 2003; Zohar ve Marshall, 2000; Zohar, 2004; Wigglesworth, 2011). İ̧verenler örgütlerin verimini artırmak için işgörenlerin iş memnuniyetlerini ve örgütsel bağlılıklarını artırmayı önemsedikleri görülmektedir.

Örgütlerde iş memnuniyeti ve örgütsel bağılığı etkilediği tespit edilen önemli değişkenlerden biri de çalışanların ruhsal zekâlarıdır (Malik ve Naeem, 2011; Ravikumar ve Dhamodharan, 2014). Ruhsal zekâ sosyal bilimlerin gelişim süreci içinde belli aşamalardan geçtikten sonra ortaya çıkabilmiştir. İnsanlık hep doğru düşünebilme, çözüm üretebilme, çevresiyle iletişim kurabilme ve iş yapabilme kapasitesini sorgulamış ve artırmaya çalışmıştır. Bu doğrultuda önce insanların zekâlarının zihinsel birer süreç (Intelligence Quotient) olduğu düşünülmüş ve bu zekâ türü ile ilgili araştırmalar yapılmıştır. Daha sonra insanların duygulara sahip olduğunun ve duyguların insanların zihinsel zekâlarını etkilediğinin farkına varılmasıyla duygusal zekânın (Emotional Quotient) varlığı kabul edilmiştir (Akgemici ve Bekiş, 2013). Bununla birlikte zekâ türlerinin farklılıklar gösterdiği vurgulanarak her bireyde farklı zekâ türlerinin daha baskın olduğu ifade edilmiştir. Çoklu zekâ olarak ifade edilen bu zekâ türleri; sözel zekâ, mantıksal zekâ, görsel zekâ, Sosyal zekâ, müziksel zekâ, duyusal zekâ ve bireysel zekâ olarak çeşitlendirilmiştir (Aydıntan, 2009).

2000'li yıllardan itibaren alanyazında zihinsel ve duygusal zekâ türlerini düzenleyen, yön veren ve uyumlu çalışmasını sağlayan bir zekâ türü olan "ruhsal zekâ" ön plana çıkmıştır (Zohar ve Marshall, 2000; Zohar, 2004; Wigglesworth, 2011; Bekiş, 2006). Ruhsal zekâ diğer zekâ türleri ve yetenekleri uyum içinde çalıştıran, birleştiren ve davranışa dönüştüren bir yönetmen gibi işlev görmektedir. Wigglesworth (2011) Ruhsal zekânın diğerlerini yönetmesini görsel olarak ifade etmek için bir piramit yapmış ve en üste ruhsal zekâyı, onun altına duygusal zekâyı ve en alta ise zihinsel zekâyı koymuştur. Aydıntan (2009), ruhsal zekâyı kişinin yeniliklere açıklığıyla kendi değerleri ve yeteneklerinin birleşimi olarak ifade etmektedir. Bu ruhsal zekâ özelliklerine sahip olan kişi, zihinsel zekânın ürettiği çözümler ile duygu ve değerlerini çatıştırmadan birbiriyle uyumlu ve anlamlı çalışmasını sağlar.

Ruhsal zekânın özelliklerini Bozdağ (2005); inanma gücü, gerekçe gücü, ısrar gücü, kanaat gücü, ruhsal etkileşim gücü ve ilahi irade gücü olarak belirtmektedir. Zohar (2004) ise bu özelliklerin; öz bilinç, kendiliğindenlik, bütüncüllük, şefkat, farklılıkları kutlamak, alan bağımsızlığı, temelden sorgulama eğilimi, yeniden tasarlama yeteneği ve alçakgönüllülük olarak ifade etmiştir (Bekiş, 2006). Kanaat gücünün yüksek olması, alçak gönüllülük, bütüncüllük ve şefkat özelliklerini taşıyan ruhsal zekânın iş memnuniyetini olumlu etkileyeceği düşünülmektedir. 
Iş memnuniyetinin ilk tanımlanması 1911 yılında Taylor ve Gilbert tarafından yapılmıştır (Şahin, Aydoğdu, Yoldaş, (2011). Hawthorne araştırmaları da iş memnuniyeti ve üretim arasındaki etkiyi ölçmeye çalışan deneyler olarak ifade edilebilir. Kısaca çalışanların yaptıkları işlerden duydukları haz olarak ifade edilen iş memnuniyetinin farklı tanımları da bulunmaktadır. Yılmaz ve Ceylan (2011) çalışanların işlerini sevme derecesi olarak ifade ederken, Çetinkanat (2000) iş memnuniyetini, çalışanların işin durumuna göre geliştirdiği duygu olarak tanımlamıştır. Gibson, Ivancevich \& Donnelley (2000)'e göre iş memnuniyeti çalışanın işi ile ilgili iyi hisleri olarak tanımlamıştır. İs memnuniyetini çalışanın beklentileri ile işin gerçek durumu arasındaki fark olarak tanımlanmış olup bu fark ne kadar az ise çalışanın iş memnuniyeti de o kadar az olacaktır (Tengilimoğlu, 2005).

İ̧ memnuniyeti ile ilgili ilişkili birçok değişken bulunmaktadır. Alanda yapılan çalışmalar incelendiğinde iş memnuniyetini yaş, eğitim düzeyi, sağlık durumu, kuruluşa üye olma, işletme büyüklüğü ve çalışma saatleri, kişisel faktörler, örgütsel faktörler gibi değişkenler etkilerken kişilik özelliklerinin de önemli olduğu belirtilmektedir (Yazıcı, Altun, 2013; Yılmaz, Ceylan, 2011). Bu bağlamda iş memnuniyeti ile ilişkili araştırılması gereken örgütsel faktörlerin başında örgütsel bağlılık gelmektedir.

Örgütler ellerindeki sermayelerini etkili bir şekilde kullanarak verimli çalışmalar yapmak ve kaliteli ürünler elde etmeyi amaçlamaktadırlar. Çalışanların örgütlerine duydukları bağlıık da elde edilen ürünler üzerinde önemli bir etkiye sahiptir. Örgütsel bağlılık 20. yüzyılın ikinci yarısından bu yana bilimin ilgisini çekmiş ve araştırmalara konu edilmiştir (Korkmaz, 2011). Yapılan bu araştırmalarda öğretmenlerde örgütsel bağlıı̆ın okulların etkili olması arasında önemli rol oynadığı bulunmuştur (Hoy ve Miskel, 1987; Lee, 2013; Selamat, Nordin ve Adnan, 2013).

Mowday, Steers ve Porter'in (1979) yaptıkları "Örgütsel Bağlıı̆ın Ölçülmesi" adlı çalışmada örgütsel bağlılı̆ın üç temel yönüne vurgu yapmışlardır. Bunlardan birincisi çalışanlar örgütün değer ve amaçlarını güçlü bir inançla kabul ederler. İkincisi çalışanlar örgüt için ciddi anlamda çaba göstermeye istekli olurlar. Sonuncusu ise çalışanlar örgüt üyeliğini sürdürme noktasında güçlü bir arzuya sahip olurlar. Bir başka ifade ile bireyler, örgütün değer ve amaçlarını özümseyerek kendilerini örgütle özdeşleştirdiklerinde bu durum örgütsel bağlıık olarak ifade edilir (Serin ve Buluç, 2012)

Örgütsel bağlılığı Grusky (1966) çalışanın örgüte olan bağlılık duygusunun gücü olarak tanımlarken, Batemen ve Strasser (1984) örgüt ile birey arasındaki uyumun seviyesi olarak ifade etmiştir (Turan, Karadağ ve Bektaş, 2011). Örgütsel bağlılık örgüt açısından büyük önem taşımaktadır. Örgütsel bağlılık çalışanlarda iş memnuniyetini artırmakta (Valentine vd., 2002), çalışanın örgütten ayrılma isteğini azaltmakta (Robbins ve Coulter, 2003) ve örgütün etkililiğine katkıda bulunmaktadır (Hoy, Tarter ve Kottkamp, 1991).

Bazı araştırmacılar örgütsel bağlılığı üç boyutu ile ele almışlardır: Duygusal bağlılık, devam bağ|ılığı ve normatif bağ|ılık. Duygusal bağ|ılıkta bireyin amaç ve değerleri ile örgütüm amaç ve değerleri uyum içindedir. Birey bu örgütün içinde olmaya gönüllüdür. Devam bağlılığında birey ile örgütün değer ve amaçları birbiriyle çok uyuşmasa da birey örgütten ayrılmanın getireceği maddi sorunlar nedeniyle örgüte devam eder. Normatif bağlılıkta ise birey örgütten ayrılmak ister ancak dış baskılar nedeniyle örgütte kalmaya devam eder (Sezgin, 2010).

Ruhsal zekâ ile iş memnuniyeti arasındaki ilişkiyi inceleyen ve anlamlı bulan birçok araştırma yayınlanmıştır. Ravikumar ve Dhamodharan (2014) çalışmaları ruhsal zekâ ile iş 
memnuniyeti ilişkisinin anlamlı düzeyde olduğunu ortaya koymuştur. Yine benzer şekilde Drahma ve Kanaga (2014) çalışmaları da iş memnuniyeti ile ruhsal zekâ arasında birçok yönden ilişki olduğunu ortaya koymuşlardır. Ruhsal zekâ ile iş memnuniyeti arasındaki ilişkiyi inceleyen başka bir çalışmayı da Kaur (2013) yapmıştır. Bu çalışmada da ruhsal zekâ ile iş memnuniyeti arasında anlamlı bir ilişki ortaya çıkmıştır.

Ruhsal zekâ ile örgütsel bağlılık arasındaki ilişkiyi inceleyen araştırmalara baktığımızda ruhsal zekâ düzeyi yüksek olan bir çalışanın örgütsel bağlılığı da artmaktadır. Kalantarkousheh (2013) yaptığı çalışma ile ruhsal zekânın örgütsel bağlılığı anlamlı düzeyde yordadığını ortaya koyarken, Ravikumar ve Dhamodharan (2014) yaptıkları çalışmada ruhsal zekânın hem örgütsel bağıı̆ı̆ı hem de iş memnuniyetini anlamlı düzeyde etkilediğini ortaya koymuştur.

Iş memnuniyeti ve örgütsel bağ|ılık alanyazında en çok çalışılan konulardan birisi olmuştur. Bu çalışmaların büyük bir kısmında iş memnuniyetinin örgütsel bağlılığı artırdığı ortaya konulmuştur (Valentine vd., 2002; Gökçe, 2014; Karataş ve Güleş, 2010; Sığrı ve Basım, 2006; Izgar, 2008).

Yapılan araştırmaları sonuçları açısından değerlendirmek gerekirse; Gökçe (2014) iş memnuniyetinin azaldığı durumlarda örgütsel bağııı̆ı̆ın da azaldığını ortaya koyarken, diğer araştırmalar iş memnuniyeti artarken örgütsel bağııığın da arttığını ortaya koymaktadır. İş doyumu ve örgütsel bağlılık cinsiyet açısından değerlendirildiğinde kadınların erkeklere göre daha yüksek iş memnuniyetine sahip olduğu görülmektedir (Gökçe,2014; Izgar,2008). Örgütsel bağlılık açısından ise kadınlar ve erkekler arasında anlamlı bir değişiklik bulunmamaktadır.

Çalışanların iş memnuniyet ve örgütsel bağıılık düzeyleri hem eğitim yöneticilerini hem de örgütün kendisini ciddi anlamda ilgilendirmektedir. Örgütsel bağlılık ve iş memnuniyeti yüksek çalışanların işten ayrılmalarının azalmaktadır (Porter, Steers, Mowday ve Boulian, 1974; Dolu, 2011). İşten ayrılmaların çok olduğu örgütler çabuk yıpranır ve maddi kayıplar yaşarlar. Örgütün verimi için önemli olan örgütsel vatandaşlığın artmasında da iş memnuniyeti ve örgütsel bağlılık önemli öncüllerdir (Williams ve Anderson, 1991). Çalışanların gönüllü olarak gerçekleştirdikleri bu tür davranışlar örgüt için önemlidir. Örgütün çevre ile rekabeti ve verimi için iş menuniyetinin ve örgütsel bağlılığa neden olan değişkenlerin araştırılması önem arz etmektedir.

Yapılan araştırmalar ruhsal zekânın örgütsel bağlıı̆ı (Malik ve Naeem, 2011; Kalantarkousheh ve arkadaşları, 2013) ve iş memnuniyetini (Ravikumar ve Dhamodharan, 2014; Rastgar, Davoudi, Oraji ve Abbasian, 2012; Ghorbani, Haghighi, Mohammdali Tajrishi, ve Rasteh-moghadam, 2012; Hajizadeh, Delavaryan, Mehrabifar ve Taherifar, 2015) etkileyen öenmli bir değişken olduğunu göstermiştir. Ayrıca iş memnuniyeti ile örgütsel bağlılık arasında pozitif bir ilişki olduğu pek çok araştırmada bulunan başka bir sonuçtur (Valentine vd., 2002; Izgar, 2008; Sığrı ve Basım, 2006). Fakat örgüt verimi için çok önemli iş memnuniyeti ile örgüt bağlılık değişkenlerinin ruhsal zekâ ile birlikte inceleyen çalışmaya ülkemizde rastlanmamıştır. Bu araştırma ile söz konusu üç değişkenin birlikte incelenmesi ülkemizde alanyazına katkı açısından önemlidir.

Yine bu araştırma ile ruhsal zekânın örgütsel bağıı̆ı̆ını etkilemesinde aracılık yapan iş memnuniyeti gibi başka değişkenlerin incelenmesi sağlanacaktır. Eğer aracı değişkenler incelenmediği durumda ruhsal zekânın örgütsel bağlılığa etkisi sonuçları eksik ve hatalı olacağı için aracılık etkisinin tespiti çok önemlidir. Çünkü ruhsal zekânın örgütsel bağıılığa direk etkisinin yanında başka aracı değişkenler üzerinden dolaylı etkileri de olabilir. Sonuç olarak ruhsal zekânın örgütsel bağlılı̆a etkisinde iş memnuniyeti değişkeninin aracılık etkisinin olup olmadığının tespiti bu alandaki önemli bir boşluğu gidereceği düşünülmektedir. 
$\mathrm{Bu}$ araştırma ile amaçlanan çalışanların ruhsal zekâları, örgütsel bağlılıkları ve iş memnuniyetleri arasındaki ilişkinin otaya konulmasıdır. Araştırma problemleri sırasıyla şöyledir: Rushsal zekâ iş doyumunu yordamakta mıdır? Rusal Zekâ örgütsel bağlılığı yordamakta mıdır? Ruhsal zekânın örgütsel bağlıı̆ğa etkisinde iş doyumunun aracılık etkisi var mıdır? Araştırmacı ruhsal zekânın örgütsel bağlılığı hem doğrudan etkilediğini hem de iş memnuniyetini aracı kılarak etkilediğini hipotez olarak kabul ederek araştırmasını "Şekil 1" deki gibi modellemiştir.

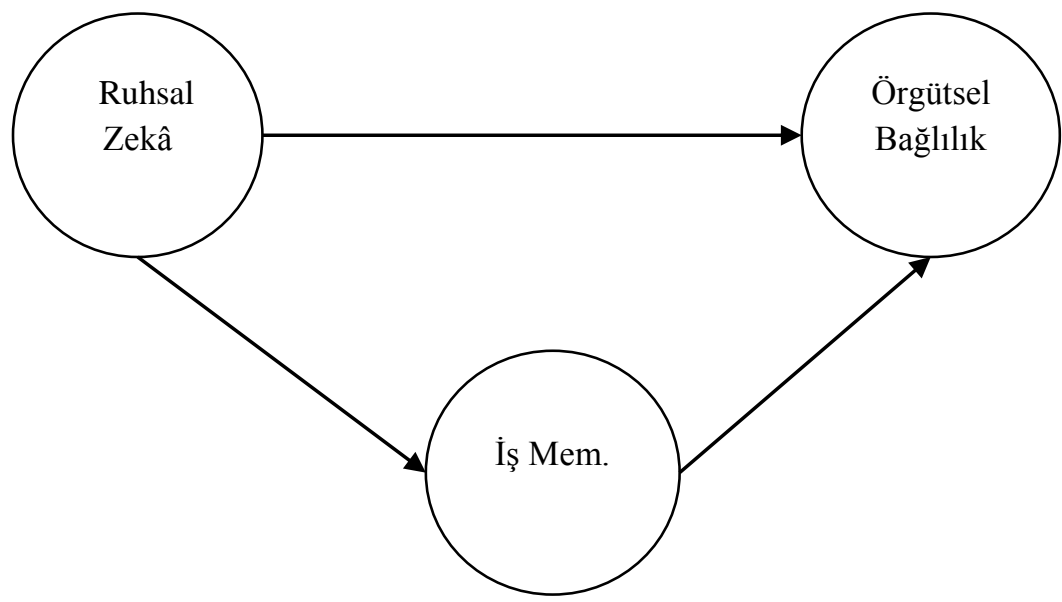

Şekil 1: Araştırmanın model tasarımı

\section{YÖNTEM}

Bu çalışmada öğretmenlerin ruhsal zekâ ve iş memnuniyetleri ile öğretmenlerin örgütsel bağlılığı arasındaki ilişki incelenmesi amaçlandığından, araştırma deseni ilişkisel tarama modeli olarak belirlenmiştir. iliş̧kisel tarama modeli (Karasar, 2002); iki ya da daha fazla değişken arasındaki şu anda var olan bir durumu veya daha önce var olan bir durumu olduğu şekliyle ve ilişkili olan değişkenlerle korelasyon yaparak ortaya koymaya yarayan bir modeldir. Araştırmamızda bağımsız değişken olarak ruhsal zekâ belirlenmiştir. Bağımlı değişkenlerimiz ise iş memnuniyeti ve örgüt bağlılık olmaktadır.

Araştırma için gerekli verilerin toplanması amacıyla üç ölçme aracı (Ruhsal Zekâ Ölçeği, İş Memnuniyeti Ölçeği ve Örgütsel Bağlılık Ölçeği) kullanılmıştır. Üç ölçekde de beşli likert tipi (1:Hiç katılmıyorum- 5:Tamamen Katılıyorum) maddelerden oluşmaktadır.Ruhsal zekâ ölçeği 2004 yılında Cook, Macaulay ve Coldicott tarafından geliştirilmiştir. Ruhsal zekâ ölçeğinin Türkçe uyarlaması Aydıntan (2009) tarafından yapılmıştır. Yapılan güvenirlik analizi sonucunda güvenilirlik (Cronbach alpha) katsayısı 0.92 olarak bulunmuştur. Ruhsal zekâ anketi Kabullenme, özbenlik, amaçlar ve değerler olmak üzere üç boyuttan oluşmaktadır. İş Memnuniyeti Ölçeği (Short Form Minnesota Satisfaction Questionnaire -MSQ) Weiss, Davis, England ve Lofquist (1967) tarafından geliştirilmiştir. Ölçeğin Türkçeye uyarlaması Baycan (1985) tarafından yapılmıştır. Yapılan güvenirlik analizi sonucunda güvenilirlik (Cronbach alpha) katsayısı 0.88 olarak bulunmuştur. İ̧ memnuniyeti ölçeği içsel memnuniyet ve dışsal memnuniyet olmak üzere iki boyuttan oluşmaktadır. Örgütsel bağlılık ölçeği olarak Allen ve Meyer (1991) tarafından geliştirilen ve Karakuş (2005) tarafından Türkçe’ye çevrilen örgütsel bağlılık ölçeği kullanılmıştır. Ölçek için yapılan güvenirlik analizi sonucunda güvenilirlik (Cronbach alpha) katsayısı 0.89 olarak bulunmuştur. Örgütsel bağlılık anketi ise üç boyuttan oluşmaktadır. Bu boyutlar, duygusal bağlılık, devam bağııığı ve normatif bağlılıktır. 


\subsection{Araştırma Grubu}

Bu araştırmanın çalışma evrenini, Malatya il merkezinde bulunan ilköğretim okullarında 2014-2015 eğitim-öğretim yılında görev yapmakta olan 2095 sınıf öğretmeni oluşturmaktadır. Araştırmanın çalışma grubunu, çalışma evreninden basit seçkisiz örnekleme yöntemiyle yansız olarak seçilmiş 155 öğretmen oluşturmaktadır. Alınan örneklem evreni temsil etmekten uzak olduğu için araştırma grubu denilmiştir.

Araştırmaya katılan öğretmenlerin cinsiyet, medeni durum ve yaş değişkenlerine göre frekans ve yüzdelikleri Tablo 1'de gösterilmiştir.

Tablo 1

Araştırmaya Katılan Öğretmenlerin Demografik Özellikleri

\begin{tabular}{llcc} 
Değişkenler & Kategoriler & $\mathbf{N}$ & \% \\
\hline \multirow{2}{*}{ Cinsiyet } & Erkek & 123 & 79,4 \\
& Kadın & 32 & 20,6 \\
\hline \multirow{2}{*}{ Medeni Hal } & Evli & 118 & 76,1 \\
& Bekar & 37 & 23,9 \\
\hline \multirow{3}{*}{ Yaş } & 30 ve altı & 46 & 29,7 \\
& $31-40$ arası & 69 & 44,5 \\
& 41 ve üstü & 40 & 25,8 \\
\hline
\end{tabular}

Tablo 1 incelendiğinde katılımcıların çoğunluğunun cinsiyetlerinin erkek olduğu (\% $79,4)$ görülmektedir. Katılımcıların medeni hallerine baktı̆̆ımızda çoğunluğu evlidir $(\% 76,1)$. Yaş değişkenine göre katılımcıların dağılımında orta yaş grubundaki öğretmenlerin sayısı ( $N=69$; $\% 44,5)$ diğer gruplara göre oldukça fazla olduğu söylenebilir.

\section{2. İstatistiksel Analiz}

Verilerin analizi SPSS 17.0 istatistik paket programlarında yapılmıştır. Veriler hiyerarşik çoklu doğrusal regresyon yöntemi kullanılarak analiz edilmiştir. Verilerin analizine başlamadan önce veriler eksik değer, aykırı değer, normallik, çoklu değişme açısından incelenmiş, diğer bir ifadeyle analizlerin sayıltıları test edilmiştir.

Regresyon analizine geçmeden önce değişkenler arasında korelasyon olup olmadığına bakılmıştır. Korelasyon analizinde Büyüköztürk (2011), katsayı değerleri (r) 0,10 ile 0,29 arasında ise zayıf, 0,30 ile 0,70 arasında ise orta 0,70 ile 1,0 arasında ise değişkenler arasında yüksek düzeyde bir ilişki bulunduğunu ifade etmektedir.

Korelasyon olduğu görülünce ardından sebep değişkenin önce gerçekleşip gerçekleşmediğine bakılmıştır. Daha sonraki analizde bağımsı değişkenlerin bağımlı değişkenleri yordamasının incelenmesi için cinsiyet, yaş ve kıdem değişkenlerinin kontrol altına alındığı hiyerarşik çoklu regresyon analizi yapılmıştır. Test edilmek istenen model: “Öğretmenlerin ruhsal zekâ düzeyleri öğretmenlerin örgütsel bağlıı̆̆ını hem doğrudan hem de iş memnuniyeti aracılı̆̆ıyla etkilemektedir". Bu araştırmada öğretmenlerin ruhsal zekâ düzeylerinin örgütsel bağılığını yordamasında öğretmenlerin iş memnuniyeti düzeylerinin aracılık (mediation) etkisi araştırılmıştır. 
Illk olarak Baron ve Kenny (1986) tarafından ortaya atılan aracılık etkisi, iki değişkenin birbiri arasındaki ilişkide üçüncü bir değişkenin aracı olması durumu şeklinde tanımlanabilir. íki değişken arasındaki ilişkide üçüncü değişkenin aracılık ettiğini ya da dolaylı bir etki olduğunu söylemek bazı şartlara bağlıdır.

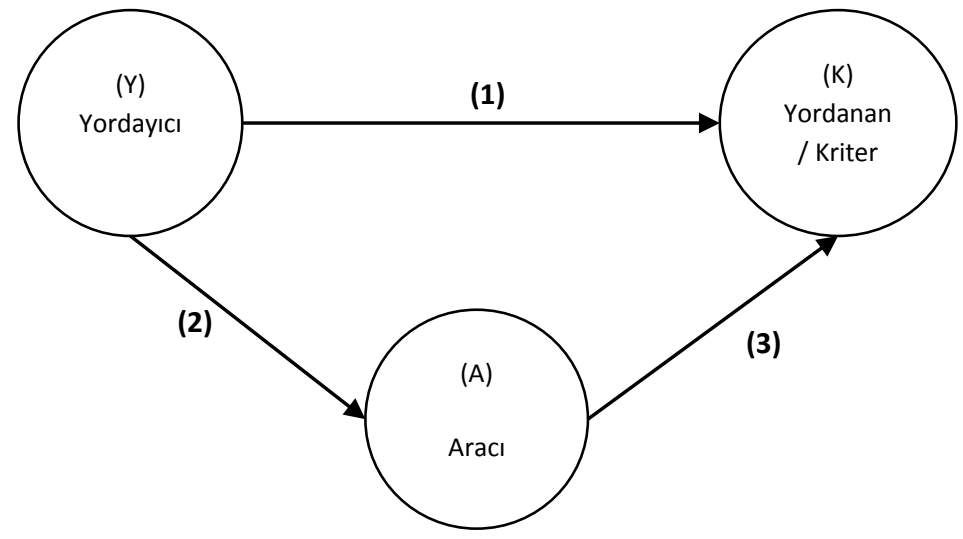

Şekil 2. Baron ve Kenny (1986) modelinde aracılık etkisi

Şekil 2'de görüleceği üzere burada elimizde (Y) Yordayıcı, (K) Yordanan/ Kriter ve (A) Aracı şeklinde üç değişkenimiz olsun. Baron ve Kenny (1986:1177) regresyon analizi ile aracılık etkisinin ispatı için aşağıdaki dört şartın yerine getirilmesi gerektiğini söylemiştir. (1) Y, K'yı anlamlı bir şekilde yordar. (2) Y, A'yı anlamlı bir şekilde yordar. (3) Y'nin etkisinin kontrol edilmesi ile $A, K^{\prime} y ı$ yordar. (4) A'nın etkisinin kontrol edilmesi ile $Y^{\prime}$ nin $K^{\prime} y ı$ yordamasında anlamlı bir düşüş olur ya da bu ilişki istatistiksel olarak anlamsız olur.

Dördüncü adımda Y'nın K'yı yordamasının anlamsız çıkması durumunda A'ya "tam aracı" değişken, eğer Y'nin K'yı yordamasında almamı bir azalma var ise A'ya "kısmi aracı" değişken denir (Frazier, Tix ve Barron, 2004:126). Kısmi aracılık etkisinde Y'nin K'ya hem doğrudan etkisi hem de A üzerinden dolaylı etkisi olduğunu söyleyebiliriz. Böyle bir modelde eğer A düşünülmeden (kontrol edilmeden) hesaplanan Y'nin K'ya etkisi, aslında doğrudan ve dolaylı etkilerin toplamıdır.

Aracılık etkilerinin anlamlılı̆ını test etmek için alanyazında 14 ayrı aracılık test etme yöntemi bulunmaktadır. Literatürde oldukça sık kullanılan ve en güvenilir sonuçlar ürettiği belirlenen Sobel testi bu araştırmada kullanılmıştır (Şimşek, 2007). Sobel testinin kullanımı için Jose (2003) tarafından geliştirilen ve web sayfasında kullanıma açık MedGraph-ı programı kullanılmıştır.

\section{BULGULAR}

Regresyon analizine başlamadan önce bağımlı değişken, bağımsız değişken ve aracı değişken arasında korelasyon olup olmadığı kontrol edildi. Öğretmenlerin ruhsal zekâları, iş memnuniyetleri ve örgütsel bağlııklarına ait korelasyon değerleri Tablo 2 de görülmektedir. 
Tablo 2

Öğretmenlerin Ruhsal Zekâ, Örgütsel Bağlılık, işs Memnuniyeti puanlarının genel ortalamalarının korelasyon tablosu

\begin{tabular}{cccc} 
& İş Memnuniyeti & Ruhsal Zekâ & Örgütsel Bağlılık \\
\hline İş Memnuniyeti & 1 & & \\
\hline Ruhsal Zekâ & $0,296^{* *}$ & 1 & 1 \\
\hline Örgütsel Bağlılık & $0,701^{* *}$ & $0,376^{* *}$ &
\end{tabular}

Tablo 2 de görüldüğü gibi öğretmenlerin ruhsal zekâ ortalamaları ile iş memnuniyeti puanlarının ortalamaları arasında zayıf $(0,296)$ bir ilişki vardır. İş memnuniyeti ile örgütsel bağlılık arasında güçlü $(0,701)$ bir ilişki olduğu görülmektedir. Ruhsal zekâ ile örgütsel bağlıık arasında ise orta derecede bir ilişkinin $(0,376)$ olduğu görülmektedir.

\subsection{Ruhsal Zekâ, İ̧̧ Memnuniyeti ve Örgütsel Bağlılık Arasındaki İlişki}

Öğretmenlerin genel ruhsal zekâ düzeylerinin örgütsel bağlılıklarına etkisinde iş memnuniyeti düzeylerinin aracılık etkisini araştırmak için yapılan hiyerarşik çoklu doğrusal regresyon analizine ilişkin bulgular ve sonuçlar yer almaktadır. Aşağıda yapılan aracılık testi analizinde öğretmenlerin ruhsal zekâ düzeylerinin örgütsel bağlılığa etkisi incelenirken, iş memnuniyeti kontrol değişkeni olarak modele alınmıştır.

Tablo 3. Öğretmenlerin Ruhsal Zekâ Düzeylerinin Örgütsel Bağlılığa Etkisinde iş Memnuniyetinin Aracılık Etkisini Belirlemeye Yönelik Hiyerarşik Çoklu Regresyon Analizi Sonuçları

\begin{tabular}{|c|c|c|c|c|c|c|}
\hline & Bağımsız Değişkenler & B & Std. Hata & Beta & $\mathrm{t}$ & $\mathrm{p}$ \\
\hline \multirow{5}{*}{ 1. Adım } & (Sabit) & 0,864 & 0,621 & & 1,39 & 0,166 \\
\hline & Kıdem & $-0,009$ & 0,020 & $-0,112$ & $-0,435$ & 0,664 \\
\hline & Yaş & 0,013 & 0,020 & 0,166 & 0,643 & 0,521 \\
\hline & Cinsiyet (dummy) & 0,037 & 0,111 & 0,026 & 0,335 & 0,738 \\
\hline & Ruhsal Zekâ & 0,539 & 0,111 & 0,369 & 4,87 & $0,000 * * *$ \\
\hline \multirow{6}{*}{ 2. Adım } & (Sabit) & $-0,005$ & 0,470 & & $-0,011$ & 0,991 \\
\hline & Kıdem & $-0,007$ & 0,015 & $-0,091$ & $-0,473$ & 0,637 \\
\hline & Yaş & 0,010 & 0,015 & 0,127 & 0,657 & 0,512 \\
\hline & Cinsiyet (dummy) & 0,068 & 0,083 & 0,048 & 0,819 & 0,414 \\
\hline & Ruhsal Zekâ & 0,262 & 0,086 & 0,179 & 3,02 & $0,003^{* *}$ \\
\hline & İş Memnuniyeti & 0,615 & 0,056 & 0,647 & 10,90 & $0,000 * * *$ \\
\hline
\end{tabular}

$* \mathrm{p}<.05, * * \mathrm{p}<.01, * * * \mathrm{p}<.001$

1. Adımda $\Delta \mathrm{R}^{2}=0,135^{* * *}$

2. Adımda $\Delta R^{2}=0,380 * * *$

Tablo 3’te görüldüğü gibi, 1. adımda demografik değişkenlerden cinsiyet, yaş ve kıdem öğretmenlerin ruhsal zekâ düzeyleri değişkenleri kontrol edildikten sonra, 2. adımda öğretmenlerin iş memnuniyeti puanı doğrudan tanımlama (enter) metodu ile modele eklenmiştir. Yapılan hiyerarşik çoklu doğrusal regresyon analizi sonucunda, iş memnuniyeti modele eklendikten sonra, ruhsal zekânın örgütsel bağlılık üzerindeki etkisi $\beta=.369$ 'dan 
$\beta=.179$ 'a düşmektedir. İş memnuniyeti modele eklendikten sonra ruhsal zekânın etkisinin azalması (fakat hâlâ bu etkinin anlamlı olması) iş memnuniyetinin bu ilişkide kısmi aracı (partial mediator) bir değişken olduğunu göstermektedir. Yani ruhsal zekâ hem doğrudan hem de iş memnuniyeti aracılığıyla örgütsel bağlıık üzerinde etkide bulunmaktadır.

1. Adımda öğretmenlerin ruhsal zekâ düzeyinin örgütsel bağlııklarını doğrudan etkileme düzeyi sorgulanmıştır. Çıkan değerler $\Delta R^{2}=0,135$ ve $p<.001$ düzeyindedir. Bu değerler öğretmenlerin ruhsal zekâsının örgütsel bağlığı doğrudan anlamlı bir şekilde yordadığını göstermektedir. $\Delta R^{2}$ değeri ise örgütsel bağlılığın \% 13 ünün ruhsal zekânın doğrudan etkisi ile açıklanabileceğini ifade etmektedir.

2. Adımdaki değerlere bakıldığında yine $p<.001$ düzeyindedir. $\mathrm{Bu}$ değerler öğretmenlerin ruhsal zekâsının örgütsel bağlığı doğrudan anlamlı bir şekilde yordadığını göstermektedir. $\Delta R^{2}=0,380$ değeri ise örgütsel bağlılığın \% 38'i ruhsal zekânın doğrudan ve iş memnuniyeti aracılığı ile açıklanabileceğini ifade etmektedir.

Bulunan aracılık etkisinin anlamlılığına ilişkin Sobel testini uygulamak için Tablo 3'teki bazı veriler, Jose (2003)'ün MedGraph-I programına girilmiş ve aşağıdaki Tablo 4 elde edilmiştir.

Tablo 4

Öğretmenlerin Ruhsal Zekô Düzeylerinin, Örgütsel Bağlılığını Yordamasında iş Memnuniyeti Düzeylerinin Aracılık Etkisinin anlamlılığına ilişskin Sobel Testi Analizi Sonuçları

\begin{tabular}{|l|l|}
\hline Aracılık Tipi & Kısmi \\
\hline Sobel Z değeri & 3,555 \\
\hline Anlamlıık & 0,000 \\
\hline Direk etki & 0,179 \\
\hline Dolaylı etki & 0,197 \\
\hline Toplam etki & 0,376 \\
\hline
\end{tabular}

Tablo 4'te görüleceği üzere aracılık etkisinin anlamlılı̆ı için MedGraph-I programına Tablo 3'teki bazı verilen girilmesi ile yapılan Sobel testinde, iş memnuniyetinin aracılık etkisinin, p<.001 düzeyinde anlamlı olduğu görülmektedir. Aracılık etkilerini tespit etmek için yapılan analizlerin sonuçlarına genel olarak bakıldığında; ruhsal zekânın örgütsel bağlılığa toplam etkisinde $\beta=.369$ olmaktadır, iş memnuniyeti kontrol edildiğinde ruhsal zekânın örgütsel bağılıı üzerine direk etkisinde $\beta=.179$ olmaktadır. Aradaki fark $\beta=.197$ dolaylı etki olarak iş memnuniyetinin aracılık etkisinden kaynaklanmaktadır. Bu aracılık etkileri ve genel model Şekil 3'te görülmektedir. Şekilde değişkenlerin birbirini yordaması tek yönlü okla gösterilmiştir. Regresyon tablosundaki standardize edilmiş beta katsayıları okların üzerinde belirtilmiştir. 


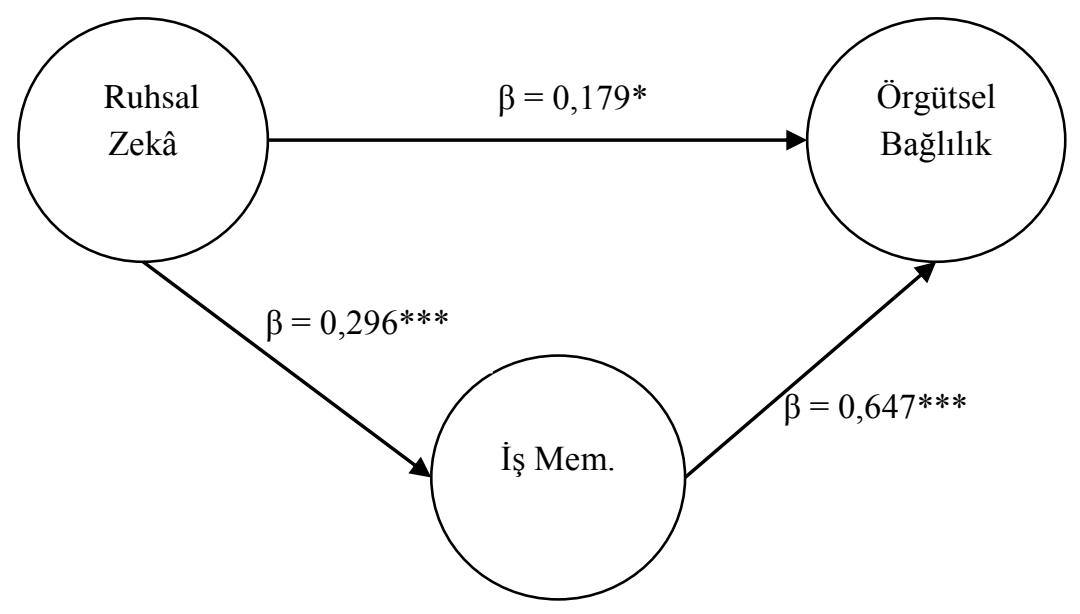

Şekil 3. Öğretmenlerin ruhsal zekâ düzeylerinin, örgütsel bağlılığını yordamasında iş memnuniyeti düzeylerinin aracılık etkisi ve standardize edilmiş beta katsayıları $\left({ }^{*} p<.05, * * p<.01, * * * p<.001\right)$

Şekil 3'te görüleceği üzere öğretmenlerin ruhsal zekâlarının genel örgütsel bağlılığı yordamasında iş memnuniyetlerinin kısmi aracılık etkisi vardır $(Z=3,555, p<.001)$. Buna göre öğretmenlerin ruhsal zekâları genel örgütsel bağlılıklarını doğrudan etkilediği gibi, aynı zamanda iş memnuniyetleri üzerinden dolaylı olarak etkilediği de görülmektedir. Öğretmenlerin ruhsal zekâ düzeylerinin yüksek olması, hem kendi iş memnuniyetleri üzerinde dolaylı olarak hem de doğrudan olarak genel örgütsel bağılıılarını artıracaktır.

\section{SONUÇ VE TARTIŞMA}

Bu araştırmada öğretmenlerin ruhsal zekâlarının örgütsel bağlııklarını olumlu ve anlamlı olarak etkilediği bulunmuştur. Öğretmenlerin ruhsal zekâ düzeyleri arttıkça örgütsel bağlıık düzeylerinin de arttığı ortaya çıkmıştır. Bu araştırmadaki bulguya benzer şekilde yapılan farklı araştırmalarda da öğretmenlerin ruhsal zekâ düzeylerinin kendi örgütsel bağlıık düzeylerini üzerinde olumlu yönde etkiler oluşturduğu saptanmıştır (Malik ve Naeem, 2011; Kalantarkousheh ve arkadaşları, 2013). Banka sektöründe çalışanlar üzerinde benzer bir çalışma yapan Ravikumar ve Dhamodharan (2014) da ruhsal zekâ düzeyi ile örgütsel bağlıık düzeyi arasında anlamlı ve olumlu yönlü bir ilişki olduğu sonucuna ulaşmıştır. Bu bulgular ışığında evrendeki öğretmenlerin ruhsal zekâ düzeylerinin örgütsel bağlılığı olumlu ve anlamlı bir şekilde yordadığı ifade edilebilir.

$\mathrm{Bu}$ araştırmanın bir başka bulgusu ise ruhsal zekânın iş memnuniyetini olumlu yönde yordadığıdır. Bizim araştırmamıza benzer farklı araştırmalarda da benzer sonuçlar ortaya çıkmıştır. Drahma ve Kanaga (2014) ortaokul öğretmenleri üzerinde yaptığı çalışmada iş memnuniyeti ile ruhsal zekâ arasında olumlu ve anlamlı bir ilişki olduğunu ortaya koymuşlardır. Kaur'un (2013) yaptığı çalışmada da ruhsal zekânın iş memnuniyetini güçlü şekilde olumlu olarak yordadığı sonucuna ulaşmıştır. Benzer şekilde çalışma yapan araştırmacılar ruhsal zekâ düzeyi ile iş memnuniyeti düzeyi arasında anlamlı ve olumlu bir ilişki olduğu sonucuna ulaşmışlardır (Ravikumar ve Dhamodharan, 2014; Rastgar, Davoudi, Oraji ve Abbasian, 2012; Ghorbani, Haghighi, Mohammdali Tajrishi, ve Rasteh-moghadam, 2012; Hajizadeh, Delavaryan, Mehrabifar ve Taherifar, 2015). Bu sonuçlar göstermektedir ki öğretmenlerin ruhsal zekâ düzeyleri arttıkça iş memnuniyetleri de artacaktır. 
Bir başka sonuç ise iş memnuniyetinin örgütsel bağlılığı anlamlı ve olumlu yönde etkilediğidir. Bu sonuç alanyazında çok sayıda çalışma ile desteklenmektedir. Izgar'ın (2008) okul yöneticileri üzerinde yaptığı çalışmada, Sığrı ve Basım, (2006) kamu ve özel sektörü karşılaştıran araştırmalarında, Karataş ve Güleş'in (2010) ilköğretim öğretmenleri üzerinde yaptığı, Valentine vd. (2002) genç çalışanlar üzerinde yaptığı araştırmalarda da hep benzer sonuçlar çıkmıştır: İş memnuniyeti arttıkça örgütsel bağlıık da artmaktadır. Gökçe'nin (2014) araştırmasında ise duruma tersten bakılmış ve iş memnuniyetinin azaldığı durumlarda örgütsel bağııı̆̆ın da azaldığı sonucuna ulaşılmıştır. Bizim araştırmamızın sonucunda öğretmenlerin iş memnuniyeti düzeyleri ile örgütsel bağlılıkları doğru orantılı olduğu verisine ulaşılmıştır. İş memnuniyeti arttıkça örgütsel bağıııı da artacaktır.

Bu araştırmanın bir sonucu ruhsal zekânın örgütsel bağlılığı doğrudan etkilemesinin yanında iş memnuniyeti aracılığıyla dolaylı olarak da etkilediğidir. Dolaylı etkilemede, ruhsal zekâ iş memnuniyetini olumlu yönde etkilemekte, iş memnuniyeti de örgütsel bağlılığı olumlu yönde etkilemektedir. Böylece ruhsal zekâ örgütsel bağılığı hem doğrudan etkilemekte hem de dolaylı olarak ya da iş memnuniyetini aracı kılarak etkilemektedir. Bu araştırmanın bulguları gibi, Cherati ve arkadaşları (2013) da yaptıkları araştırmanın sonucunda ruhsal zekânın örgütsel bağlılığa etkisinde iş memnuniyetini aracı etken olarak bulmuşlardır.

Sonuç olarak eğitim yöneticileri için öğretmenlerin iş memnuniyetleri ve örgütsel bağ|ııkları önemli olduğundan hem kendilerinin ruhsal zekâları hakkında hem de öğretmenlerinin ruhsal zekâları hakkında bilgi edinmeli ve ruhsal zekâyı önemsemelidirler. Çünkü ruhsal zekâ bir örgüt olarak okulu ve çalışanların okula bağlılıklarını etkilemektedir. Ruhsal zekâ sadece örgütsel bağlıı̆ı̆ değil aynı zamanda iş memnuniyetini de etkilemektedir. Bu bakımdan örgütler için çok önem arz eden iki hususu anlamlı olarak etkileyen ruhsal zekâ bir eğitim yöneticisi tarafından dikkate alınmalıdır.

Öğretmenlerin sahip oldukları ruhsal zekâ onların iş memnuniyeti düzeylerini ve örgütsel bağlılık düzeylerini olumlu yönde etkilediği görülmektedir. Yöneticiler, okullarda tüm personelin iş memnuniyetini ve örgütsel bağlılığını artırmak için ruhsal zekâ düzeylerini göz önünde bulundurmalıdır. Okullarda ruhsal zekâ ile ilgili farkındalığın artırılması için seminer ve etkinlikler düzenlenmesi yararlı olacaktır. Eğitim fakülteleri öğretmen yetiştirirken ruhsal zekâ kavram ve içeriğini öğretim programlarına almaları yararlı olacaktır.

Bu araştırmada ortaya çıkan ruhsal zekânın örgütsel bağııı̆̆ı yordamasında iş memnuniyetinin ara yordayıcı olduğudur. Araştırmacılar, başka hangi değişkenlerin aracılık etkileri olabileceğini inceleyebilirler. Bu araştırmada ruhsal zekâ ve iş memnuniyeti tarafından etkilenen örgütsel sonuç değişkenleri olarak örgütsel bağlıık ele alınmıştır. Araştırmacılar "örgütsel bağlılık" dışındaki (işten ayrılma isteği, adanmışlık, tükenmişlik vb.) duygu temelli sonuç değişkenlerini bağımlı değişken olarak alıp inceleyebilirler.

\section{KAYNAKLAR}

Akgemici, T. ve Bekiş, T. (2013). Liderlikte ruhsal zekâ üzerine bir alan araştırması. Selçuk Üniversitesi iktisadi ve Idari Bilimler Fakültesi Sosyal ve Ekonomik Araştırmalar Dergisi, 13(26), 283- 300.

Allen, N.J. \& Meyer, J.P. (1991). A tree-component conceptualitazation of organizational commitment. Human Resource Management Review,1(1), 61-89.

Aydıntan, B. (2009). Ruhsal zekânın dönüştürücü liderlik üzerine etkisini araştıran uygulamalı bir çalışma. Atatürk Üniversitesi iktisadi ve Idari Bilimler Dergisi, 23(2), 257-274. 
Baron, R.M. ve Kenny, D.A. (1986). The moderator-mediator variable distinction in social psychological research: Conceptual, strategic and statistical considerations. Journal of Personality and Social Psychology, 51(6), 1173-1182.

Baycan, A. (1985). An analysis of the several aspects of job satisfaction between different occupational groups. (Yayımlanmamış Yüksek Lisans Tezi). Boğaziçi Üniversitesi Sosyal Bilimler Enstitüsü, İstanbul.

Bekiş, T. (2006). Liderlikte ruhsal zekâ üzerine uygulamalı bir çalışma. (Yayımlanmamış Yüksek Lisans Tezi). Selçuk Üniversitesi, Konya.

Bateman, T. S., \& Strasser, S. (1984). A longitutudinal antecedents of organizational commitment. Academy of Management Journal, 27(1), 95-112.

Bozdağ, M. (2005). Ruhsal zekâ. İstanbul: Nesil.

Büyüköztürk, Ş. (2011). Sosyal bilimler için veri analizi el kitabı. Ankara: Pegem.

Cherati, H., Mahdavi, I., \& Rezaeian J., (2013). The mediating role of job satisfaction between spiritual intelligence and organizational commitment. International Journal of Research in Organizational Behavior and Human Resource Management, 1(1), 1-11.

Rastgar, D. A. A., Davoudi, S. M. M., Oraji, S. I. A. V. A. S. H., \& Abbasian, M. E. H. D. I. (2012). A study of the relationship between employees' spiritual intelligence and job satisfaction: A survey in Iran's banking industry. Spectrum,1(2), 57-74.

Sarah, C., Macaulay, S., \& Coldicott, H. (2004). Change management excellence: using the four intelligences for successful organizational change. London: Kogan Page Limited.

Çetinkanat, C. (2000). Örgütlerde güdülenme ve iş doyumu. Ankara: Anı.

Dolu, B. (2011). Bankacılık sektöründe çalışanların örgütsel bağlıık düzeyleri üzerine bir araştırma. (Yayımlanmamış Tezsiz Yüksek Lisans Bitirme Projesi). Süleyman Demirel Üniversitesi, Isparta.

Drahma R. S., \& Kanaga L. (2014). Relationship between spiritual intelligence and job satisfaction- a conceptual study. Global Journal for Research Analysis, 3(3), 95-97.

Frazier, P.A., Tix, A.P. ve Barron, K.E. (2004). Testing moderator and mediator effects in counseling psychology research. Journal of Counseling Psychology, 51(1), 115-134.

Ghorbani, M., Haghighi, M., Mohammdali Tajrishi, I., Rasteh-moghadam, A. (2012). The relationship between spiritual intelligence and organizational commitment in public sector. Quarterly Journal of Management and Development Process, 25(3), 67-92.

Gibson, J. L., Ivancevich, J. M. \& Donnelley, J. H. (2000). Organizations- behaviour- structureprocesses.10th. Edition. Boston: McGraw- Hill.

Gökçe, A.T. (2014). Okullarda bilgi uçurma: iş doyumu ve örgütsel bağlılık ilişkisi. Dicle Üniversitesi Ziya Gökalp Eğitim Fakültesi Dergisi, 22, 261-282

Grusky, O. (1966). Career mobility and organizational commitment. Administrative Science Quarterly, 10(4), 488-503.

Hajizadeh, R., Delavaryan, F., Mehrabifar, F., Taherifar, P. (2015). The relationship between spiritual intelligence and job satisfaction of teachers in special schools in Kerman province. Applied Mathematics In Engineering, Management and Technology, 3(1), 492497 
Hoy, W. K., \& Miskel, C. W. (1987). Educational administration:theory, research, and practice. New York: Random House.

Hoy, W. K., Tarter, C. J., \& Kottkamp, R. B. (1991). Open schools / healthy schools: Measuring organizational climate (1 st ed.). Newbury Park: SAGE Publications.

Izgar, H. (2008). Okul yöneticilerinde iş doyumu ve örgütsel bağlılık. Selçuk Üniversitesi Ahmet Keleşoğlu Eğitim Fakültesi Dergisi. 25, 317- 334.

Jose, P.E. (2003). MedGraph-I: A programme to graphically depict mediation among three variables: The internet version version 2.0. Victoria Univesity of Wellington, Wellington, New Zealand. Retrieved [13.09.2010] from http://www.victoria.ac.nz/staff/paul-josefiles/medgraph/medgraph.php.

Kalantarkousheh, S. M., Sharghi N., Soleimani M., \& Ramezani S. (2013). The role of spiritual Intelligence on organizational commitment in employees of universities in tehran province, Iran. Procedia - Social and Behavioral Sciences, 140, 499 - 505.

Karakuş, M. (2005). Ortaöğretim kurumlarında görev yapan öğretmenlerin örgütsel adanmışlık düzeyleri -Elazığ ili örneği. (Yayımlanmamış Yüksek Lisans Tezi). İnönü Üniversitesi Sosyal Bilimler Enstitüsü, Malatya.

Karasar, N. (2002). Bilimsel araştırma yöntemleri. Ankara: Nobel.

Karataş, S. ve Güleş, H. (2010). İlköğretim okulu öğretmenlerinin iş tatmini ile örgütsel bağlılığı arasındaki ilişki. Uşak Üniversitesi Sosyal Bilimler Dergisi, 3(2), 74-89.

Kaur M. (2013). Spiritual intelligence of secondary school teachers in relation to their job satisfaction. International Journal of Educational Research and Technology, 4(3), 104 109.

Korkmaz, M. (2011). İlköğretim okullarında örgütsel iklim ve örgüt sağlığının örgütsel bağlılık üzerindeki etkisi. Kuram ve Uygulamada Eğitim Yönetimi, 17(1), 117-139.

Lee, I. C. (2013). The influences of school supervisors' leadership styles upon organizational effectiveness: using organizational commitment and organizational change as mediators. The Journal of Human Resource and Adult Learning, 9(2), 105-123.

Malik, M. E., \& Naeem, B. (2011). Role of spirituality in job satisfaction and organizational commitment among faculty of institutes of higher learning in Pakistan. African Journal of Business Management, 5(4), 1236.

Mowday, R. T., Steers, R. M., \& Porter, L. W. (1979). The measurement of organizational commitment. Journal of Vocational Behavior, 14(2), 224-247.

Porter, L. W., Steers, R. M., Mowday, R. T., \& Boulian, P. V. (1974). Organizational commitment, job satisfaction, and turnover among psychiatric technicians. Journal of applied psychology, 59(5), 603.

Ravikumar T., \& Dhamodharan D., (2014). Impact of spiritual Intelligence on organizational commitment and job satisfaction of employees in banking sector. The International Journal Research Journal of Economics \&Business Studies, 5(3), 1-9

Robbins, S. P., \& Coulter, M. (2003). Management (7th ed.). New Jersey: Prentice Hall.

Selamat, N., Nordin, N., \& Adnan, A. A. (2013). Rekindle teacher's organizational commitment: the effect of transformational leadership behavior. Procedia-Social and Behavioral Sciences, 90, 566-574. 
Serin M. K. ve Buluç, B. (2012). İlköğretim okul müdürlerinin öğretim liderliği davranışları ile öğretmenlerin örgütsel bağ|ııkları arasındaki ilişki. Kuram ve Uygulamada Eğitim Yönetimi, 18(3), 435-459

Sezgin, F. (2010). Öğretmenlerin örgütsel bağlılı̆ının bir yordayıcısı olarak okul kültürü. Eğitim ve Bilim, 35(156), 142-159

Sığrı, Ü. ve Basım, N. (2006). İş görenlerin iş doyumu ile örgütsel bağlılık düzeylerinin analizi: kamu ve özel sektörde karşılaştırmalı bir araştırma. SÜ iiBF Sosyal ve Ekonomik Araştırmalar Dergisi, 6(12), 131- 154

Şahin, S., Aydoğdu, B. ve Yoldaş, C. (2011). Duygusal zekâ ve iş doyumu arasındaki ilişkiler: Eğitim müfettişleri üzerinde bir araştırma. Illköğretim Online, 10(3), 974-990.

Şimşek, Ö.F. (2007). Yapısal eşitlik modellemesine giriş: temel ilkeler ve LISREL uygulamaları. Ankara: Ekinoks.

Tengilimoğlu, D. (2005). Hizmet işletmelerinde liderlik davranışları ile iş doyumu arasındaki ilişkinin belirlenmesine yönelik bir araştırma. Ticaret ve Turizm Eğitim Fakültesi Dergisi, 1, 23-45.

Turan, S., Karadağ, E. ve Bektaş, F. (2011). Üniversite yapısı içerisinde öğrenen örgüt ve örgütsel bağlılık ilişkisi üzerine bir araştırma. Kuram ve Uygulamada Eğitim Yönetimi, $17(4), 627-638$

Valentine, S., Godkin, L., \& Lucero, M. (2002). Ethical context, organizational commitment, and person-organization fit. Journal of Business Ethics, 41(4), 49-360.

Yılmaz, A., \& Ceylan, Ç. B. (2011). illköğretim okul yöneticilerinin liderlik davranış düzeyleri ile öğretmenlerin iş doyumu ilişkisi. Kuram ve Uygulamada Eğitim Yönetimi, 17(2), 277-394.

Weiss, D.J., Dawis, R.W., England, G.W., \& Lofquist, L.H. (1967). Manual for the minnesota satisfaction quesitionnaire. Washington: Minnesota Studies.

Wigglesworth, C. (2011). Integral theory (also called AQAL theory) and its relationship to spiritual intelligence and the SQi assessment. http://www.deepchange.com/resources. Erişim: 23.12.2015

Williams, L. J., \& Anderson, S. E. (1991). Job satisfaction and organizational commitment as predictors of organizational citizenship and in-role behaviors.Journal of management, 17(3), 601-617.

Zohar, D. (2004). How the Bush administration has deminished America's spiritual capital. Tikkun, 19(5), 40-44.

Zohar, D. ve Marshall, İ. (2000). Ruhsal zekâmızla bağlantı kurmak. Burak Erdemli ve Kemal Budak (Çev.). İstanbul: Meta. 


\section{SUMMARY}

Contemporary organizations are aware of the importance of their employees' engagement to them not only in the sense of material aspect but also in the sense of spiritual aspect. Because of this reason, employers need to search for their employees' spiritual satisfaction as well as their satisfaction about income. The productivity and efficiency level of an employee who does not have any organizational commitment is a really big question. According to the new management approach, job satisfaction and organizational commitment are considered as important capital.

One of the most important variables affecting job satisfaction and organizational commitment in organizations is the spiritual intelligence of employees. Spiritual intelligence emerged after passing some certain stages within the development process of social sciences. Humanity have always questioned and tried to improve the capacity to think straight, find solutions and communicate with the environment and do business. Human intelligence has been considered as a mental process and then some research have been conducted on this type of intelligence. It has been noticed that people have emotions and these emotions affect people's mental intelligence. Finally presence of emotional intelligence has been accepted.

During 2000's, "spiritual intelligence" which regulates, guides, and provides consistent work between mental and emotional intelligence has come to the forefront in literature. Spiritual intelligence acts as a director that runs different types of intelligence and capabilities harmoniously, combines them, and converts them into behaviors. To visually express spiritual intelligence managing others, scientist drew a pyramid and put spiritual intelligence to the highest, emotional intelligence below it, and mental intelligence at the lowest layer. Meanwhile, some scientists refer to spiritual intelligence as a combination of openness to innovations and person's own values and capabilities. A person with high spiritual intelligence can combine the solutions produced by mental intelligence with his emotions and values in harmony.

As it is aimed to investigate the relationship between spiritual intelligence and job satisfaction of teachers and their organizational commitment; in this study, research design is determined as relational screening model. Spiritual intelligence has been identified as an independent variable. Meanwhile, the dependent variables are job satisfaction and organizational commitment.

To collect the necessary data for research three measurement tools (Spiritual Intelligence Scale, Job Satisfaction and Organizational Commitment Scale) were used. Each of these scales consists of fivepoint Likert-type (1: Totally disagree - 5: Completely Agree) items. Spiritual intelligence scale has been developed by Cook, Macaulay, and Coldicott in 2004. Aydıntan made the Turkish version of the scale. As a result of reliability analysis, the reliability coefficient (Cronbach's alpha) has been found as 0.92 . The spiritual intelligence questionnaire is composed of three dimensions: acceptance, self, purposes, and values. The Job Satisfaction Scale (Minnesota Satisfaction Questionnaire Short Form -MSQ) was developed by Weiss, Davis, England, and Lofquist. The Turkish adaptation of the scale was created by Baycan. For reliability analysis, the reliability coefficient (Cronbach's alpha) was found as 0.88 . The Job Satisfaction Scale is composed of two dimensions: internal satisfaction and external satisfaction. The organizational commitment scale developed by Allen and Meyer and translated into Turkish by Karakus, was used as scale in this study. For reliability analysis, the reliability coefficient (Cronbach's alpha) was found as 0.89 . The organizational commitment questionnaire is composed of three dimensions: affective commitment, continuance commitment, and normative commitment. The target population of the research included 2095 classroom teachers working in primary schools in Malatya during the 2014-2015 academic year. The research group included 155 teachers randomly selected from the target population using simple the random sampling method. Because of being far from representing the received target population of the research, it has been called as research group.

In this study, the spiritual intelligence of teachers affected their organizational commitment positively and meaningfully. Although teachers' spiritual intelligence levels increased, their organizational commitment levels also increased. Spiritual intelligence also predicted the job satisfaction positively. These results suggest that the increased spiritual intelligence level of teachers will lead to 
increased job satisfaction. Another result is that job satisfaction has a meaningful and positive impact on organizational commitment.

The spiritual intelligence of teachers seems to affect their job satisfaction and organizational commitment levels positively. To improve job satisfaction and organizational commitment of all staff in schools, administrators should consider their spiritual intelligence levels. Arranging seminars and events in schools will help to create awareness about spiritual intelligence. Education faculties should incorporate the concept and content of spiritual intelligence into their teacher training curriculum. 